\title{
UMA INVESTIGAÇÃO ENTRE O CONCEITO DE CAMPO ELÉTRICO E AS FORMAS DE MEDIAÇÕES NO ENSINO DE FÍSICA
}

\author{
AN INVESTIGATION BETWEEN THE FORMS OF MEDIATION THE ELECTRIC FIELD \\ CONCEPT IN PHYSICS TEACHING
}

Graciela Paz Meggiolaro' ${ }^{1}$ Agostinho Serrano de Andrade Neto², Antônio Vanderlei dos Santos ${ }^{3}$

Recebido: abril/2020 Aprovado: abril/2021

Resumo: Neste trabalho, procuramos mostrar uma investigação com foco na compreensão do conceito de vetor campo elétrico por uma aluna do curso de Licenciatura em Matemática matriculada na disciplina de Física Geral III, por intermédio de uma simulação computacional no software GeoGebra. O objetivo era investigar/identificar, de acordo com a Teoria da Mediação Cognitiva (TMC) as mediações (psicofísica, social, cultural e hipercultural) determinantes na aprendizagem de vetor campo elétrico. Utilizamos a TMC como referencial, pois, ela faz uma abordagem baseada no processamento de informações, sendo capaz de explicar o funcionamento da cognição humana, uma vez que, os processos mentais de um indivíduo ocorrem a partir do processamento de informações por estruturas em seu ambiente. A partir de gestos descritivos e suas correspondentes imagens mentais, foram realizadas as análises dos dados produzidos, as quais deram indícios de que a mediação social, cultural e hipercultural estavam presentes na aprendizagem de vetores.

Palavras-chave: Teoria da Mediação Cognitiva, Campo elétrico, GeoGebra.

\begin{abstract}
In this work, we seek to show an investigation focused on the understanding of the concept of electric field vector by a student in the Mathematics Degree enrolled in the discipline of General Physics III, through a computer simulation in the GeoGebra software. The objective was to investigate / identify, according to the Cognitive Mediation Theory (CMT), the mediations (psychophysical, social, cultural and hypercultural) determinants in the learning of electric field vector. We use CMT, which takes an information-based approach and is able to explain the functioning of human cognition, since an individual's mental processes occur from the processing of information by structures in their environment. From descriptive gestures and their corresponding mental images, analyzes of the data produced were carried out, which gave evidence that social, cultural and hypercultural mediation were present in vector learning.

Keywords: Cognitive Mediational Theory, Electric field, GeoGebra.
\end{abstract}

\section{Introdução}

No Ensino Superior, a construção do conhecimento científico torna-se grande possibilidade de discussão devido às potencialidades que os cursos oferecem por intermédio do uso de tecnologias digitais. Por isso, utilizar as tecnologias em sala de aula vem mostrando-se, ao mesmo tempo, um problema e uma solução, já que, apesar de haver algumas facilidades no

http://orcid.org/0000-0001-8294-2787 - Doutora em Ensino de Ciências e Matemática (ULBRA). Professora da Universidade Federal da Fronteira Sul (UFFS), Cerro Largo, RS, Brasil. Rua Jacob Reinaldo Haupenthal, 1580, Bairro São Pedro, CEP 97900-000, Cerro Largo, RS, Brasil. E-mail: gracipmegg@gmail.com.

2 (iD http://orcid.org/0000-0002-7868-1526 - Doutor em Física (USP). Professor da Universidade Luterana do Brasil (ULBRA), Canoas, RS, Brasil. Av. Farroupilha, 8001, São José, RS, 92425-020, Canoas, RS, Brasil. E-mail: agostinho.serrano@ulbra.br.

3 (iD) http://orcid.org/0000-0002-6016-4218- Doutor em Física (UFRGS). Professor da Universidade Regional Integrada do Alto Uruguai e das Missões (URI), Santo Ângelo, RS, Brasil. Rua Universidade das Missões, 464 Universitário 98802-470 - Santo Ângelo, RS, Brasil. E-mail: vandao@san.uri.br. 
seu uso, também surge a necessidade de criar produtos e serviços que estejam de acordo com essas inovações. Uma vez que, esses novos recursos estão inseridos no contexto educacional, mas ainda se mostram objeto de polêmica e são pouco usados, por razões que vão desde a falta de treinamento dos professores até o fator econômico da escola e dos alunos.

Entretanto, inovações tecnológicas começam a fazer-se necessárias nesse ambiente. Afinal, as aulas tradicionais de professor como dono da verdade e aluno apenas ouvinte estão ficando para trás, sendo uma das inovações possíveis para utilizar em sala de aula, o uso de softwares como auxiliar na interação dos conceitos trabalhados e discutidos no Ensino da Física. Silva e Santos (2015) afirmam que o computador, ao ser introduzido no ambiente escolar, é um excelente recurso pedagógico que atuará na melhoria da qualidade do ensino.

Para Maximiliano et al. (2012), o GeoGebra pode ser um bom aliado, devido à acessibilidade de trabalhar os conteúdos, além disso, consideram apropriado ao ritmo do aluno, despertando seu interesse pelo uso das tecnologias. Merecendo um destaque por ser uma ferramenta gratuita e de fácil acesso para professores e alunos da Educação Básica e Superior, não necessitando de domínio de informática para executá-lo, sendo uma vantagem em relação a outros softwares, possibilitando aprofundar conceitos abstratos de difícil entendimento da Física e na Matemática (Meggiolaro, 2020).

Para Souza (2004) a Teoria da Mediação Cognitiva - TMC tem uma aplicação na compreensão das mudanças individuais ou coletivas associadas à introdução das novas tecnologias, como ferramentas externas ao pensamento dos indivíduos, sendo uma teoria contextualista e construtivista.

Logo, a motivação deste trabalho está em responder a seguinte pergunta: quais são as mediações, de acordo com a TMC (psicofísica, social, cultural e hipercultural), determinantes na aprendizagem de vetor campo elétrico por uma aluna do curso de Licenciatura em Matemática? A partir da pergunta, o objetivo do artigo é investigar/identificar as mediações (psicofísica, social, cultural e hipercultural) determinantes na aprendizagem de vetor campo elétrico por uma aluna do curso de Licenciatura em Matemática na aula de Física. Sobretudo, torna-se indispensável o estudo de eletrostática não apenas como memorização de métodos ou equações, mas, sim, com propostas de ensino que possam proporcionar ao aluno a sustentação teórica necessária para confrontar suas concepções iniciais na busca pela compreensão do ambiente que o cerca (Meggiolaro, 2020).

Portanto, o artigo está organizado da seguinte forma: iniciamos discorrendo sobre a Teoria da Mediação Cognitiva (TMC); metodologia utilizada na pesquisa; na seção 4, apontamos a discussão dos resultados da pesquisa; por fim, tecemos as conclusões do trabalho.

\section{Referencial teórico}

A cognição humana se dá pela interação com o ambiente que fornece à estrutura cognitiva uma capacidade adicional de processamento por meio do mecanismo de mediação psicofísica, social, cultural e hipercultural. A mediação pode ser definida como um conjunto de conceitos, esquemas e competências mais amplos que possibilitam facilidade na representação 
e manipulação do saber com maior quantidade e variedades de mecanismos de registros. Além disso, é capaz de decompor, distribuir, gerenciar e recompor tarefas cognitivas ao longo de diferentes mecanismos de mediação interna e externos utilizados.

O foco da fundamentação teórica está na compreensão da comunicação dos drivers e imagens mentais com os conceitos do campo da Eletrostática no ensino superior. Para isso, utilizaremos a Teoria da Mediação Cognitiva - TMC (SOUZA, 2004), que emprega uma abordagem baseada no processamento de informações, capaz de explicar o funcionamento da cognição humana, seu desenvolvimento e relações com a sociedade, a cultura e a tecnologia, já que os processos mentais de um indivíduo ocorrem a partir do processamento de informações por estruturas em seu ambiente, agindo como templates para agregar informações. A TMC busca explicar os impactos das tecnologias digitais no pensamento humano, apresentando uma visão da cognição como um fenômeno de processamento de informações, sendo que uma boa parte desse processamento é feita fora do cérebro.

A TMC permite explicar a comunicação entre a estrutura cognitiva do sujeito e o mecanismo externo de processamento de informações mediante representações mentais. 0 cérebro cria competências específicas para comunicar-se com este mecanismo, propiciando a aquisição de conhecimentos (RAMOS, 2015). A cognição extracerebral é uma mediação que depende das estruturas externas, as quais complementam o processamento de informações realizado pelo cérebro (SOUZA et al., 2012).

Tal mediação é composta por objeto, processamento interno e mecanismos interno e externo. Objeto: refere-se ao conceito abstrato, problema, situação ou relação em que o indivíduo busca conhecimento, aprendizagem; Processamento Interno: mecanismo fisiológico que envolve a execução individual do cérebro em operações lógicas; Mecanismos Internos: também fisiológicos, geram algoritmos que permitem a conexão, a interação entre o processamento interno do cérebro e o processamento extracerebral, que envolve gerenciamento de drivers, algoritmos, protocolos, códigos e dados; Mecanismos Externos: pertencem ao ambiente, podendo ser de diversos tipos e de capacidade variável, indo desde objetos físicos simples (dedos, pedra) até práticas sociais complexas, artefatos culturais e redes de computadores. A figura 1 mostra o esquema de como ocorre o processamento cognitivo por meio de estruturas do ambiente, responsáveis por fornecerem uma capacidade adicional de processamento de informações.

Com isso, surge uma visão da cognição humana como algo sofisticado por tratar-se de um conjunto também sofisticado de mecanismos internos e externos de processamento de informações que, juntos, formam um complexo sistema organizado. A estrutura fundamental da Mediação Cognitiva consiste no conjunto individual de mecanismos internos, o qual torna possível a conexão de estruturas externas como auxiliares de dispositivos de processamento de informações.

Segundo Brito (2013), drivers são programas responsáveis pela comunicação entre o sistema operacional de computador e o hardware conectado a ele. É por intermédio dos drivers que o sistema operacional recebe as instruções, as processa e, a partir de então, começa a "conversar" com o periférico. 
Figura 1 - Processamento cognitivo por mediação externa. (Fonte: MEGGIOLARO, 2020).

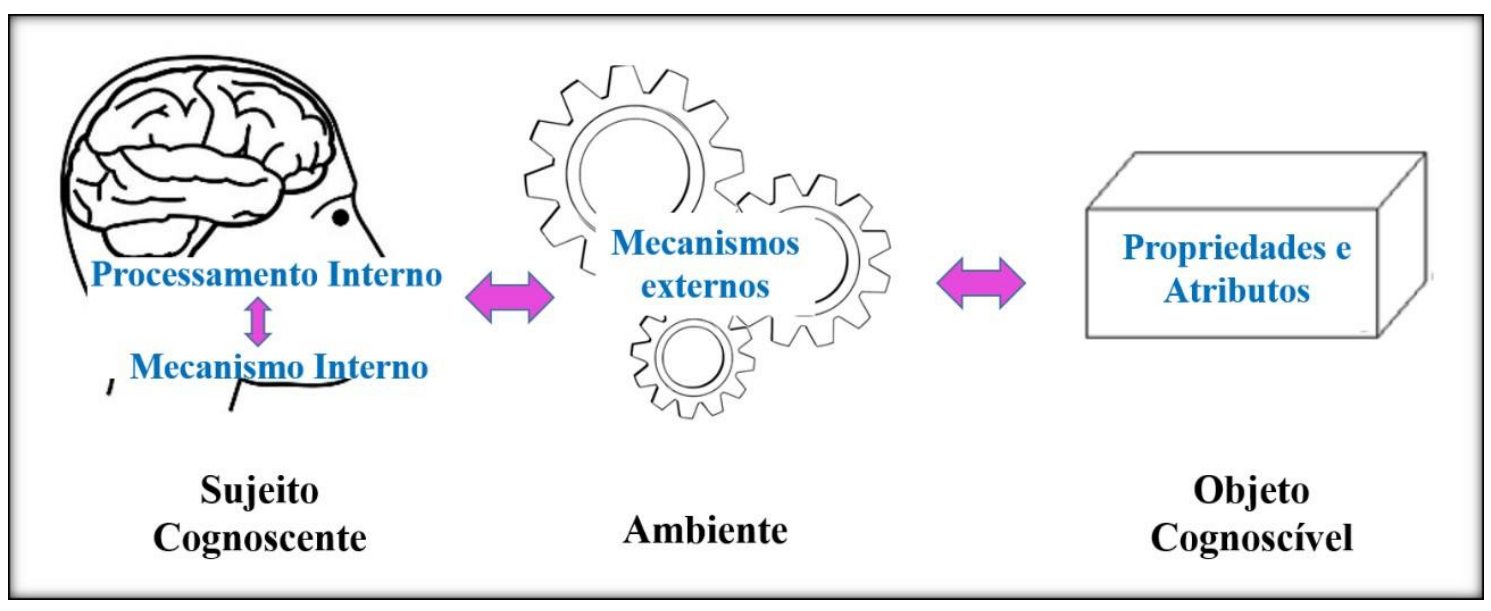

$\mathrm{Na}$ TMC, os drivers são considerados como mecanismos internos presentes na estrutura cognitiva do indivíduo que possibilitam a utilização de mecanismos externos. Portanto, os drivers permitem a comunicação entre a estrutura cognitiva do sujeito e o mecanismo externo de processamento de informações, de maneira que ambos possam interagir e o sujeito possa entender o funcionamento desse mecanismo externo, a ponto de compreender e internalizar as informações nele contidas. Tecendo-se uma analogia com a computação, tem-se uma abordagem baseada na metáfora computador-cérebro da psicologia cognitiva (RAMOS, 2015).

Existem quatro formas de mediação, de acordo com a TMC: a) a Mediação Psicofísica, relacionada às características fisiológicas do sujeito com a composição do objeto, bem como à posição espacial de ambos e à natureza do ambiente; b) a Mediação Social, quando ocorre a interação com diversos sujeitos em um mesmo ambiente; c) a Mediação Cultural, implicando a linguagem, sua organização textual e a capacidade de a sociedade relatar experiências e acontecimentos envolvendo categorizações complexas de ideias e conceitos; e d) a Mediação Hipercultural, que se utiliza do acesso à tecnologia, ao computador, às simulações, ou seja, há uso de ferramentas tecnológicas (SOUZA, 2004). Essas quatro formas de mediação serão abordadas detalhadamente a seguir.

O quadro 1 mostra a descrição feita por Souza (2004) das possíveis formas de mediações e os mecanismos envolvidos.

Quadro 1: Evolução das formas de mediação cognitiva

\begin{tabular}{|l|l|l|l|}
\hline Forma de Mediação & $\begin{array}{l}\text { Mecanismos } \\
\text { Externos }\end{array}$ & $\begin{array}{l}\text { Mecanismos } \\
\text { Internos }\end{array}$ & $\begin{array}{l}\text { Processamento } \\
\text { Extracerebral }\end{array}$ \\
\hline Psicofísica & $\begin{array}{l}\text { Física do } \\
\text { Objeto e do } \\
\text { Ambiente }\end{array}$ & $\begin{array}{l}\text { Sistemas } \\
\text { sensoriais }\end{array}$ & Percepção \\
\hline Social & $\begin{array}{l}\text { Interação em } \\
\text { grupo }\end{array}$ & $\begin{array}{l}\text { Habilidades } \\
\text { Sociais }\end{array}$ & Percepção e memória \\
\hline Cultural & $\begin{array}{l}\text { Sistemas } \\
\text { Simbólicos e } \\
\text { Artefatos }\end{array}$ & $\begin{array}{l}\text { Conhecimento } \\
\text { Tradicional e/ou } \\
\text { Formal }\end{array}$ & $\begin{array}{l}\text { Percepção, Memória, } \\
\text { Categorização } \\
\text { Aprendizagem }\end{array}$ \\
\hline
\end{tabular}




\begin{tabular}{|l|l|l|l|}
\hline Hipercultural & $\begin{array}{l}\text { Tecnologia da } \\
\text { Informação }\end{array}$ & $\begin{array}{l}\text { Conceitos e } \\
\text { Habilidades do do } \\
\text { domínio da TI }\end{array}$ & $\begin{array}{l}\text { Percepção, Memória, } \\
\text { Categorização } \\
\text { Aprendizagem, } \\
\text { Julgamento, } \\
\text { Elaboração, Tomada de } \\
\text { Decisões }\end{array}$ \\
\hline
\end{tabular}

Fonte: SOUZA (2004).

As diferentes maneiras de mediação descritas representam uma sequência cumulativa de mecanismos externos e internos, "cada novo passo representa uma verdadeira revolução cognitiva, uma enorme expansão quantitativa e qualitativa no alcance da mente humana" (SOUZA, 2004, p.79).

\section{Metodologia}

O estudo foi realizado no primeiro semestre de 2017, com cinco alunos matriculados no componente de Física III do curso de Engenharia Civil. Portanto, neste trabalho abordaremos a análise da Aluna 9 por se tratar de uma estudante do curso de Licenciatura em Matemática inserida em uma turma de Engenharia. A metodologia consistiu em seis etapas que serão explicadas abaixo:

Pré-teste: realizado individualmente com quatro situações-problema em aberto, envolvendo conceitos de campo elétrico antes da simulação computacional, com o objetivo de investigar o conhecimento inicial dos alunos sobre conceitos relacionados ao campo conceitual de eletrostática. Essencialmente, propusemos problemas que cresciam em complexidade em relação ao valor de um campo elétrico em um ponto específico do espaço (bidimensional), começando com uma única carga e adicionando uma segunda carga para que o aluno tivesse que calcular o campo resultante em um determinado ponto.

Guia de simulação computacional: O guia de atividades teve como objetivo orientar os alunos no desenvolvimento da atividade referente ao campo elétrico utilizando o GeoGebra. A atividade foi baseada na metodologia POE (Predict-Observe-Explain), onde os alunos tiveram que discutir primeiro como calcular o campo elétrico, em seguida observar e por fim explicar (TAO e GUNSTONE, 1999).

Simulação: a simulação escolhida encontra-se disponível em <https://www.geogebra.org/m/eHyU8ZmU> conforme figura 2, refere-se ao conteúdo de eletrostática, que é o estudo de cargas em repouso. Nesta simulação, é possível visualizar o vetor do campo elétrico gerado pelas cargas, onde indica a intensidade e a direção do campo.

Pós-teste: as situações problemas foram semelhantes às do pré-teste, porém, nosso objetivo foi encontrar evidências na construção e/ou modificação de imagens mentais associadas ao uso de diferentes mecanismos de mediação externa no domínio das situaçõesproblema. 
Figura 2- Simulação computacional utilizada

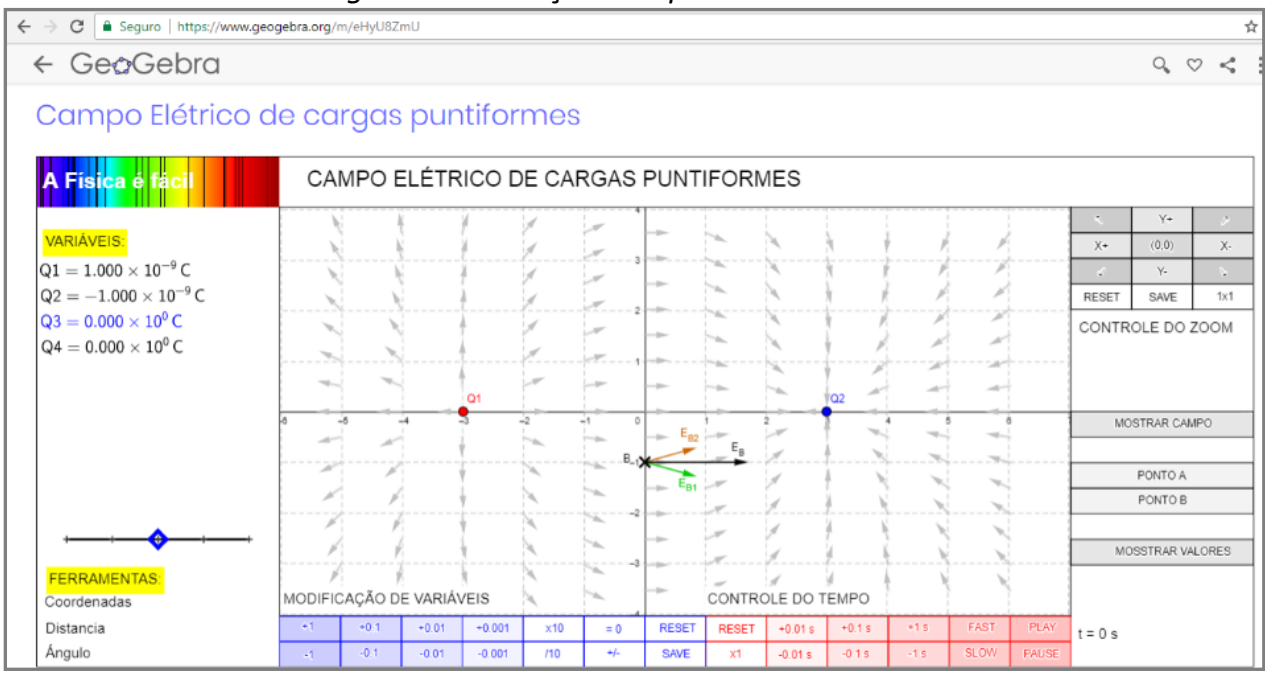

Fonte: https://www.geogebra.org/m/eHyU8ZmU

Entrevista: Foram gravadas e individuais, utilizamos a técnica Report Aloud, no qual o aluno relata seu processo de pensamento ao responder perguntas, associado à análise de gestos descritivos. Ramos (2015), Wolff (2015), Veloso (2017), Meggiolaro (2020) utilizaram a técnica Report Aloud, e observaram que, mesmo com alguns dias entre a atividade com a resolução das questões e as entrevista, o aluno lembrou das imagens mentais utilizadas na atividade.

Transcrição e gestos: Cada aluno foi renomeado para identificá-los e preservar seus nomes originais. As entrevistas foram transcritas e as imagens dos gestos foram codificadas.

Com o intuito de analisar a linguagem verbal presente na produção dos dados, utilizamos a Análise Textual Discursiva proposta por Moraes e Galiazzi (2007), que envolve identificar e isolar as afirmações dos materiais submetidos à análise, categorizando-as e produzindo textos, integrando-os à descrição e interpretação, usando o sistema de categorias construído como base para sua construção.

Análise Gestual Descritiva em relação aos gestos dos alunos, com base em Mornaghan \& Clement (1999) e Clement \& Stephens (2010), nos quais afirmam que, quando os alunos usam movimentos das mãos, estão sugerindo imagens dinâmicas de simulações mentais durante a resolução de problemas de movimento.

\section{Resultados e discussões}

Apresentaremos as evidências produzidas pela aluna 9, em relação às modificações e/ou construções de imagens mentais acerca dos conceitos de campo elétrico a partir da utilização do software GeoGebra. As análises dos dados ocorreram a partir da produção dos pré e póstestes e da entrevista realizada. Baseamos na teoria da TMC por meio das mediações cognitivas, sendo que Souza (2004) discute sobre o desenvolvimento dos processos mentais.

\section{Conceito de carga elétrica}

A aluna 9, referência a carga sendo minúscula e associa a atividade experimental desenvolvida em sala de aula "[...] eu acho que ela é muito minúscula, não é? Então, quando 
tem aquele negócio da caneta" (Figura 3), "quando tu faz na caneta... É um negócio por causa das cargas, então, provavelmente, tem mais alguma coisa".

$\mathrm{Na}$ atividade relatada pela aluna, a professora levou um canudinho e pedaços de papel, onde friccionaram o canudo no cabelo, deixando esse objeto eletricamente carregado, assim exercendo uma força sobre os pedaços de papel. Acreditamos que a mediação é psicofísica, para o foco de análise deste trabalho em relação à atividade, porém, pela TMC essa atividade foi construída culturalmente, e social, porque lembra a aula de Física III.

Figura 3 - Gesto \#PE: Processo de Eletrização. (Fonte: MEGGIOLARO, 2020).

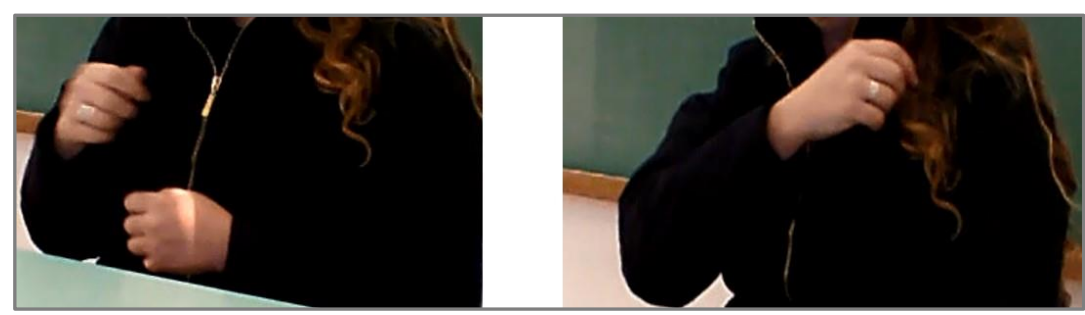

\#PE: Processo de eletrização: com a mão, a aluna simula que está aproximando a caneta do cabelo, carregando.

A respeito do depoimento da aluna 9, concordamos com Laburú, Silva e Zõmpero (2015) onde é viável analisar as ações exteriorizadas pelos alunos em relação aos conceitos científicos, porém, é preciso que o professor analise com outras representações, como as verbais.

\section{Linhas de campo elétrico}

A aluna 9 representa as linhas de campo geradas pelas cargas (Figura 4I), só no pré-teste, de forma arredondada, e, depois da simulação, não desenha mais as linhas. As linhas de campo que a aluna desenhou no pré-teste são oriundas das aulas de Física III, mediação social, onde ela relata: "no primeiro momento, a gente não tinha no que olhar, eram... Não tinha o GeoGebra, tudo no caderno que a gente tinha, que passou na aula de campo elétrico, de Física III".

Figura 4 - (I) Primeira questão do pré-teste; (II) Primeira questão do pós-teste.

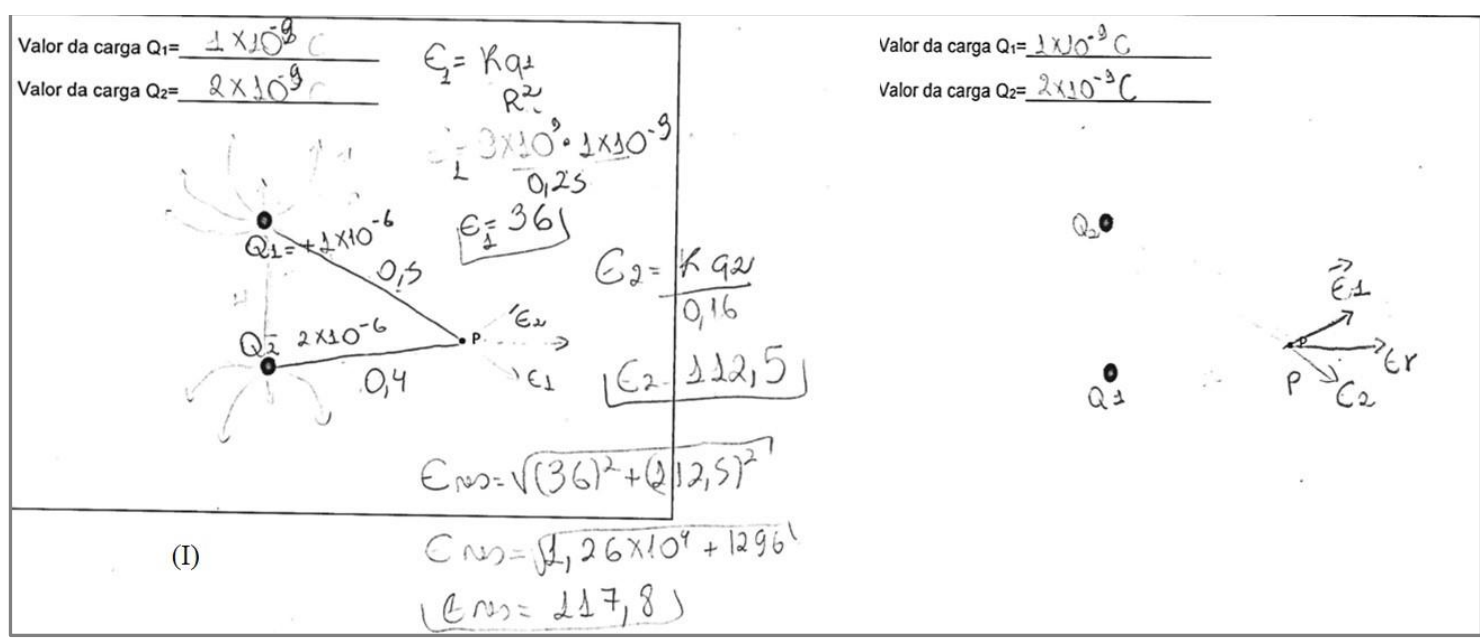

(Fonte: MEGGIOLARO, 2020). 
A aluna 9 diz: "eu pensei logo nas flechinhas, sabe... [...] O sentido delas, sabe, tipo assim, se era uma carga... Se eram duas cargas negativas, elas se repeliam" (Figura 4II); "se eram cargas positivas, elas se repeliam; se era uma carga positiva e outra negativa, elas se atraíam". Na figura 5, a aluna 9 realiza gestos que refere-se a imagem mental representando cargas de sinais negativos, no qual suas linhas de campo são para dentro, mencionando que lembrou-se da aula de campo elétrico de Física III, ou seja, observam-se imagens mentais advindas de origem social (Figura 6).

Figura 5 - Carga Elétrica Negativa: demonstra com as mãos, indicando pelo movimento dos dedos para dentro que cargas negativas se atraem.

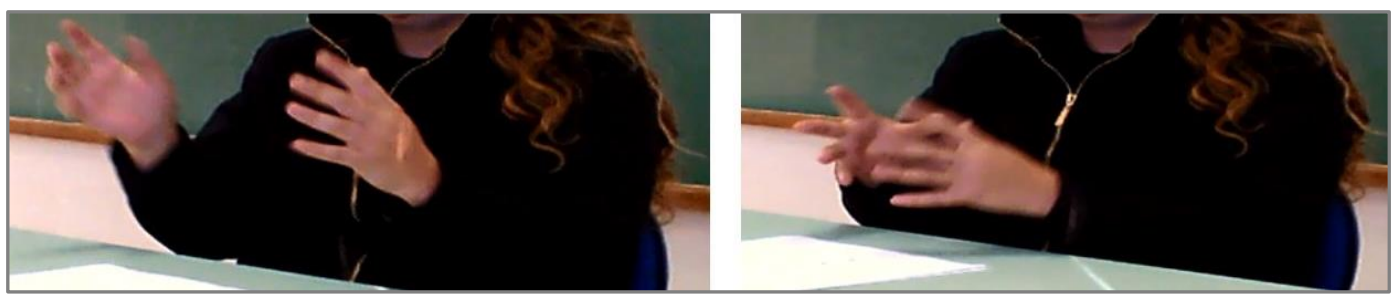

(Fonte: MEGGIOLARO, 2020).

Figura 6 - Representação do campo elétrico gerado pelas cargas, conforme trabalhado em aula.

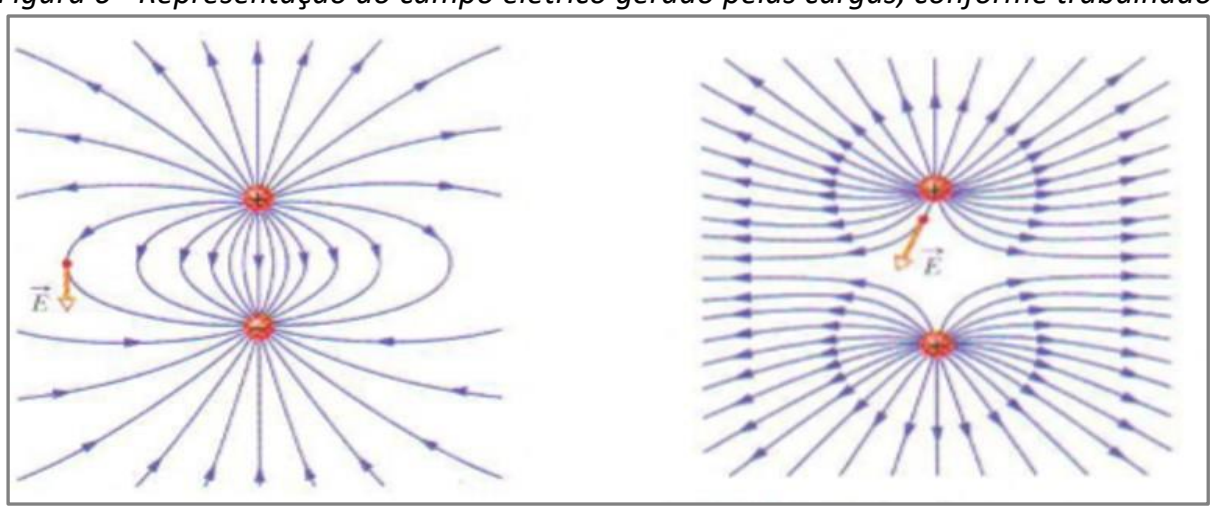

\section{Vetor campo elétrico}

A aluna 9 representou os vetores apenas na primeira situação-problema do pré-teste (Figura 4I). Nas demais, ela nem tentou desenhar, explicando na segunda situação-problema: "Aqui, eu não sei como era no começo, eu não associei com nada, que, na verdade, deveria ser diferente [...]". Contudo, após a interação com a simulação computacional no GeoGebra (Figura 7), ela adquiriu drivers na interação hipercultural e passou a representar o vetor campo elétrico em todas as situações-problema: "como eu disse antes, eu lembrei bastante era do GeoGebra, o que acontecia, não é? E a mesma situação eu tracei com uma forma do paralelogramo".

Com relação a nossa análise Mello e Silva (2012) apontaram que os alunos demostraram o desenvolvimento das habilidades características do pensamento matemático, como formular hipóteses e argumentos para resolver os problemas e apropriação dos conceitos envolvidos pelas representações extraídas das situações pela utilização do ambiente virtual pelos alunos. 
Figura 7- simulação computacional.

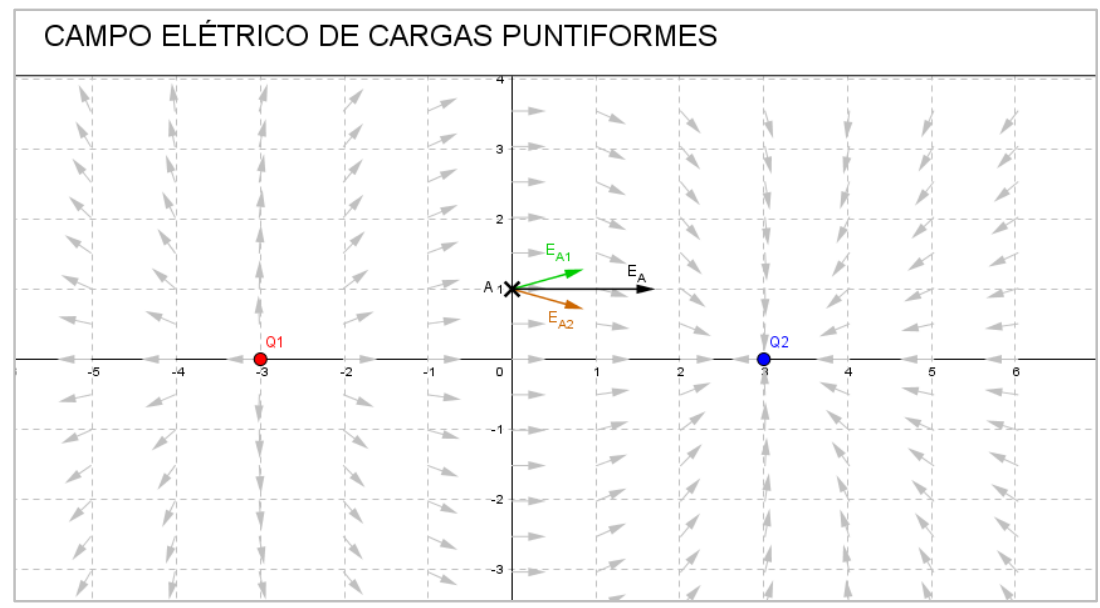

(Fonte: MEGGIOLARO, 2020).

\section{Campo elétrico relacionado a distância}

A aluna 9 respondeu que, quando aproximamos o ponto da carga, "elas ficavam maiores" (Figura 8), referindo que aumenta a intensidade e que, quando se afastava o ponto, "elas diminuíam". Ainda afirmou: "ela é inversamente proporcional à distância porque, quanto mais longe, menor é a intensidade; quanto mais perto, maior a intensidade...". Provavelmente, a imagem mental à qual a aluna refere-se está de acordo com a do GeoGebra, apontando indício da aquisição de drivers hiperculturais, uma vez que, na pergunta feita pela pesquisadora era "no GeoGebra, o que acontecia quando tu aproximasse este ponto das cargas?".

Figura 8 - Gesto \#MV: Módulo do Vetor.

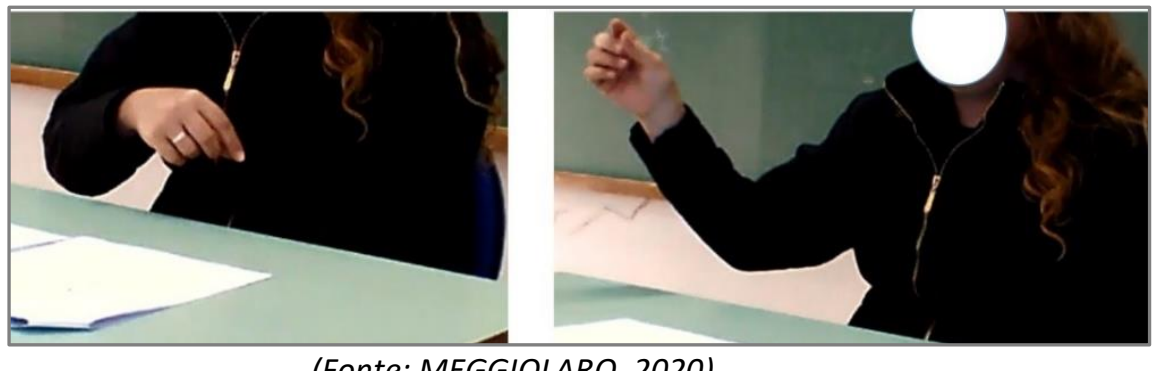

(Fonte: MEGGIOLARO, 2020).

\#MV: Módulo do vetor: representa com as mãos a intensidade dos vetores, representando a diferença de intensidades dos campos, quando próximo e quando afastado.

\section{Vetor campo elétrico resultante}

A aluna 9 representou apenas na primeira situação-problema o vetor campo elétrico resultante, na segunda e na terceira situação-problema ela não esboçou justificando: "no primeiro momento, a gente não tinha no que olhar, eram... Não tinha o GeoGebra, tudo no caderno que a gente tinha, que passou na aula de campo elétrico, de Física III". Então, para o desenvolvimento, ela utilizou os drivers sociais e culturais construídos nas aulas de Física III.

Com isso, além da representação (Figura 4I), ela determinou a equação (1)

$$
E=\frac{K q_{1}}{r^{2}}
$$

para encontrar o campo elétrico gerado pela carga $Q_{1}$ no ponto $P$. 
Para definir o campo elétrico gerado pela carga $Q_{2}$ no ponto $P$, a aluna 9 fez uso da mesma equação, mas agora com a carga $Q_{2}$. Já, para encontrar o vetor resultante gerado pelas cargas $\mathrm{Q}_{1}$ e $\mathrm{Q}_{2}$, a mesma utilizou Pitágoras (2), (Figura 4I).

$$
E_{\text {Res }}=\sqrt{E_{1}^{2}+E_{1}^{2}}
$$

$\mathrm{Na}$ entrevista, porém, ela disse que utilizou a regra do paralelogramo. Apontamos uma confusão, uma vez que a regra do paralelogramo (3),

$$
v^{2}=v_{1}^{2}+v_{2}^{2}+2 v_{1} v_{2} \cos \theta
$$

adaptando para vetores gerados pelo campo elétrico, seria descrita como (4),

$$
E_{\text {Res }}^{2}=E_{1}^{2}+E_{2}^{2}+2 E_{1} E_{2} \cos \theta
$$

Há indícios de mediação cultural quando a aluna se refere à aula de Física e de mediação cultural em relação ao caderno. Quando questionada sobre o que veio à sua cabeça quando recebeu o pós-teste, ela evidencia a mediação hipercultural:

Aluna 9: Assim, depois que a gente fez aquele negócio do GeoGebra, tipo, eu logo lembrava, pois estava nítido no software, sabe, não sei, eu consegui fixar. Depois, ainda, na prova, sabe, foi uma coisa que eu consegui associar. Se tem para o mesmo sentido, se soma, como aconteceu na prova, mesmo sentido, que eu não precisava saber o sinal, não vai te pedir o sinal. Eu me lembrava do software.

Devido a isso, na primeira situação-problema do pós-teste, a aluna conseguiu representar os vetores resultantes do campo elétrico. Percebe-se que ela adquiriu drivers hiperculturais oriundos da simulação, semelhantes aos da figura 7. Quando questionada sobre a regra do paralelogramo, ela aponta que lembrava da aula de álgebra linear e analítica, bem como do "quadro, desenhando", o que mobilizou drivers de natureza social.

Sobre a regra do paralelogramo, acreditamos que ela estava referindo-se à representação da figura 9, uma imagem que os professores utilizam na aula. Destacamos que a aluna é estudante do curso de Matemática, então, as disciplinas que são trabalhadas ao longo do curso são diferentes das dos cursos de Engenharia. Por conseguinte, sua visão sobre os conceitos são diferentes, uma vez que, o curso de Matemática está voltado à formação de professores.

Figura 9 - Representação da regra do paralelogramo.

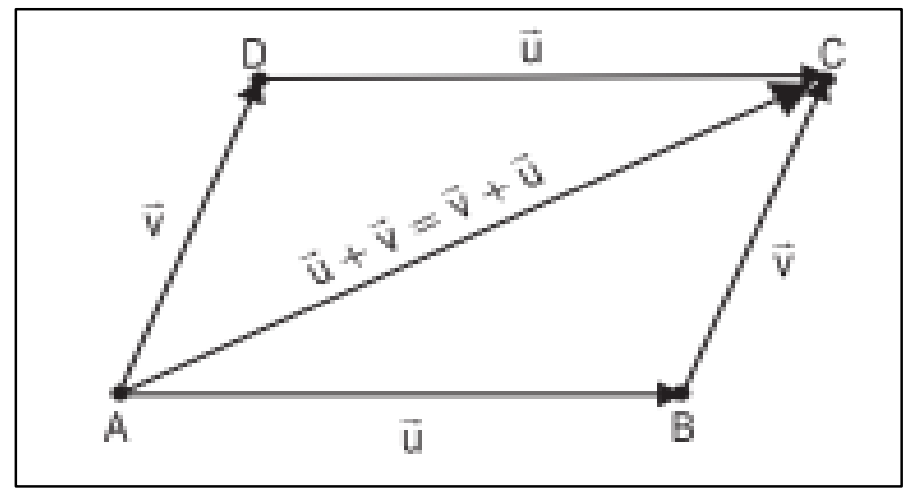

(Fonte: VENTURI, 2015, p.71). 
Nas situações-problema dois e três no pós-teste a aluna representa corretamente e volta a afirmar "como eu disse antes, eu lembrei bastante era do GeoGebra o que acontecia neh e a mesma situação eu tracei com a formula do paralelogramo" indícios da mediação hipercultural.

As simulações computacionais atuam como mediadores hiperculturais, com a finalidade de criar novas representações mentais e drivers no cognitivo do indivíduo, proporcionando uma aprendizagem dos conceitos abordados (SOUZA, 2004).

$\mathrm{Na}$ terceira situação-problema ela aponta novamente indícios de aprendizagem pela mediação social, cultural e hipercultural, uma complementando a outra.

Aluna 9: Das aulas e do software do GeoGebra, porque aqui, não sei, quando tu tem alguma coisa pra lembrar a não ser do quadro, isto te ajuda, porque aqui, eu não tinha conseguido associar, depois do software, porque tipo eu não tinha estudado pra isso e era depois da prova esse pós teste.

A partir das análises, consideramos que, para ocorrer o domínio de uma situaçãoproblema de eletrostática em relação ao seu vetor campo elétrico resultante, é importante que haja a interação aluno-professor para a compreensão dos conceitos, sendo a simulação computacional mais atrativa na visualização dos vetores.

\section{Considerações Finais}

Utilizamos a simulação computacional do Software GeoGebra, por envolver conceitos de Física e Matemática relacionado ao vetor campo elétrico, no qual através da aplicação da simulação e dos dados produzidos com o pré-teste e pós-teste, encontramos resposta para a nossa pergunta:

Quais são as mediações, de acordo com a TMC (psicofísica, social, cultural e hipercultural), determinantes na aprendizagem de vetores campo elétrico em uma aluna do curso de Licenciatura em Matemática?

A partir da análise dos dados produzidos da aluna 9, de acordo com a TMC, as mediações presentes na aprendizagem de vetor campo elétrico foram: mediação social, voltada as aulas de álgebra linear e analítica; mediação cultural, ao relacionar ao caderno, e a mediação Hipercultural, devido a atividade desenvolvida no GeoGebra, onde a aluna 9 espontaneamente evidenciou essas mediações durante a entrevista.

Ou seja, sobre os vetores gerados pelas cargas, mediação hipercultural em virtude do GeoGebr a. Em relação ao vetor resultante do campo elétrico mediação social e cultural construídos nas aulas de Física e Álgebra linear, e mediação hipercultural por lembrar do GeoGebra. Quando a aluna se refere ao conceito de carga elétrica, evidenciamos a mediação psicofísica em relação à atividade e mediação social, pois, lembra a aula de Física III. Em relação as linhas de campo elétrico indícios da mediação social relacionada a aula de Física III, e mediação cultural por lembrar do material utilizado em aula. Sobre campo elétrico produzido a uma distância r, indício da aquisição de drivers hiperculturais. 
Ao finalizar, afirmamos que o ensino do professor é importante, pois, ele orienta o processo de ensino e aprendizagem, sendo necessários recursos que façam a mediação deste conhecimento. Uma vez que, existe a necessidade de investigar como as diferentes mediações externas às quais o aluno está exposto na vida entrelaçam e conversam para o início da construção de um conceito, é o caminho para conduzir os alunos ao processo de aprendizagem.

\section{Referências}

BOWYER, J.; DARLINGTON, E. Should I Take Further Mathematics? Physics Undergraduates' Experiences of Post-Compulsory Mathematics. Physics Education. v52 n1. Jan 2017.

BRITO, E. Entenda o que são drivers, para que servem e como instalá-los. 2013. Disponível em: http://www.techtudo.com.br/artigos/noticia/2013/06/entenda-que-sao-drivers-para-queservem-e-como-instala-los.html. Acessado em 03 mar 2017.

CLEMENT, J.J; STEINBERG, M. S. Evolution of Mental Models of Eletric Circuits - A learning-aloud case study. The Journal of Learning Sciences, v.11, n.4, p.389-452, 2002.

YIN, R. K. Estudo de caso: planejamento e métodos. 2a ed. Porto Alegre: Bookman. 2001.

LABURU, C.; SILVA, O.; ZÔMPERO, A. Significados de eletrostática interpretados por meio da gesticulação de estudantes. Ciência e Educação (Bauru). v.21 n.4 Bauru. 2015.

MAXIMIANO, R. SILVEIRA, M. BELLOTI, E. ROSSINI, M. BACCILI, V. ORLANDI, A. O GeoGebra e o Ensino da Física: aprender a aprender. GeoGebra Uruguay. 2012.

MEGGIOLARO, G. Uma investigação entre os mecanismos externos de mediação e situaçõesproblema de eletrostática, em uma disciplina de física geral em nível universitário [recurso eletrônico]. Mafra, Santa Catarina. Editora da UnC, 2020.

MELLO, K; SILVA, R. Uma experiência sobre o ensino e aprendizagem de vetores no IFRS com o auxílio do GeoGebra. Cadernos do Aplicação, Porto Alegre, v. 25, n. 1, jan./jun. 2012.

MORAES, R; GALIAZZI, M. C. Análise Textual Discursiva. ljuí: Editora Unijuí, 2007.

MONAGHAN, J. M.: CLEMENT, J.J. Use of a computer simulation to develop mental simuations for understanding relative motion concepts. International Journal of Science Education. v. 21, n. 9, p. 921-944. 1999.

RAMOS, A. F. Estudo do Processo de Internalização de Conceitos de Química Utilizando Software de Modelagem Molecular: Uma proposta para o ensino médio e superior. 2015. 230 f. Tese (Doutorado - Ensino de Ciências e Matemática), Universidade Luterana do Brasil, Canoas, 2015.

ROSA, Cleci Teresinha Werner da; TRENTIN, Marco Antonio Sandini; BIAZUS, Marivane de Oliveira. Tecnologias educacionais no ensino de física: retrato das pesquisas nacionais. Ensino de Ciências e Tecnologia em Revista. Vol. 7, n. 2. jul./dez. 2017

SILVA, M. SANTOS, M. A utilização das tecnologias da informação e comunicação no ambiente escolar: uma proposta de implantação. Revista Debates em Educação. v.7. no 14. 2015. 
SOUZA, B. C.; LULA, A. M.; MOURA, A. L. N. O papel da hipercultura na atividade de consultoria: um estudo com consultores na Região Metropolitana do Recife. In: XXXVI Encontro da ANPAD. Anais. Rio de Janeiro, 2012.

SOUZA, B. C. A Teoria da mediação cognitiva: os impactos cognitivos da hipercultura e da mediação digital. Tese (Doutorado em Psicologia Cognitiva), Programa de Pós-graduação em Psicologia, Universidade Federal de Pernambuco, Recife, 2004.

VELOSO; M. S. O. Uma investigação do processo de (re)construção de conceitos de Física em atividades experimentais em cursos de Física a distância. 2017. 206f. Tese (Doutorado)- Ensino de Ciências e Matemática, Universidade Luterana do Brasil, Canoas, 2017.

VENTURI, J. J., Álgebra Vetorial e Geometria Analítica. 10ā. ed. Curitiba, PR. 2013.

WOLFF, J. F. S. As modificações de drivers prévios através da utilização de simulações computacionais: aprendizagem significativa dos conceitos de colisões verificadas através da análise das imagens mentais de estudantes universitários. 2015. 260 f. Tese (Doutorado) Ensino de Ciências e Matemática, Universidade Luterana do Brasil, Canoas, 2015. 